\title{
A CASA FENÍCIO-PÚNICA
}

Rodrigo Araújo de Lima

\section{Apresentação}

O atual redescobrimento sobre a identidade fenício-púnica vem trazendo à luz importantes aspectos sobre a organização espacial dessa cultura. Muitas escavações vêm ocorrendo no sul da Península Ibérica dialogando com outros assentamentos fenício-púnicos bem trabalhados no Mediterrâneo. Nesse texto pretendemos averiguar quatro áreas mediterrânicas onde se atesta a presença fenício-púnica, sendo elas: 1) o Levante, 2) a Península Ibérica, 3) a Sicília e 4) o Norte de África.

\section{Da fundação dos assentamentos à construção das habitações}

Atualmente nosso conhecimento sobre a questão do espaço nos assentamentos fenício-púnicos se aprofundou, graças às descobertas feitas principalmente na Península Ibérica, onde foram encontradas uma miríade de fundações orientais 1 . Os estudos fenício-púnicos na Espanha foram um dos principais impulsionadores nas investigações arqueológicas no subsolo de Gádir (Sáez Romero, 2011: 18).

Durante muito tempo considerou-se o espaço apenas o teatro das ações humanas (Febvre; Bataillon, 1925: 37) e a Arqueologia assim como a Geografia partilhavam a ideia de valorizar mais as formas das coisas do que sua formação (Santos, 2005: 21).

Estrabão, segundo Milton Santos, (2005: 30) aconselhava que os atributos de um lugar deveriam ser levados em consideração por serem

\footnotetext{
${ }_{1}^{1}$ Para citar alguns exemplos, temos em Cádis, o Yacimiento Arqueológico de lo Teatro de Títeres "La Tía Norica" descoberto em 2002 (Zamora, 2010: 203), em Huelva temos o sítio de Tierra Llana de Huelva, investigado sistematicamente desde 1990 (López Castro, 2008: 82) e o assentamento de Doña Blanca, tido como o conector da antiga Gádir (atual Cádis) com a hinterlândia rural, garantindo acesso da cidade aos recursos agrícolas (Lópes Castro, 2008: 83). Esses são alguns dos exemplos mais notórios do sul da Península Ibérica apenas com o objetivo de ilustrar a extensão da presença fenício-púnica no Ocidente.
} 
permanentes, enquanto os atributos superpostos conhecem mudanças, todavia Santos avalia que a mudança, de fato, acontece para ambos.

Um dos elementos que distingue as fundações fenícias do restante dos assentamentos de outros povos ao redor do Mediterrâneo consiste basicamente na topografia (Bondì, 1999: 311; Mezzolani, 2000: 1223). “A paisagem urbana fenícia" pode ser descrita como fundações geralmente situadas em promontórios, ou ilhas, não muito longe da costa, de preferência próximo a águas rasas ou em estreitos no mar cuja configuração assemelhe-se a um lago (Bondì, 1999: 311). (Ver fig.1),

De acordo com Markoe (2000: 68) o típico padrão de assentamento fenício constituía-se de dois distritos, a "cidade baixa" que abrigava os quarteirões fabris e residenciais e a "cidade alta" que acomodava os templos, prédios administrativos e a residência dos mais abastados. A "cidade alta" também servia como uma cidadela defensiva e era costumeiramente separada por muros.

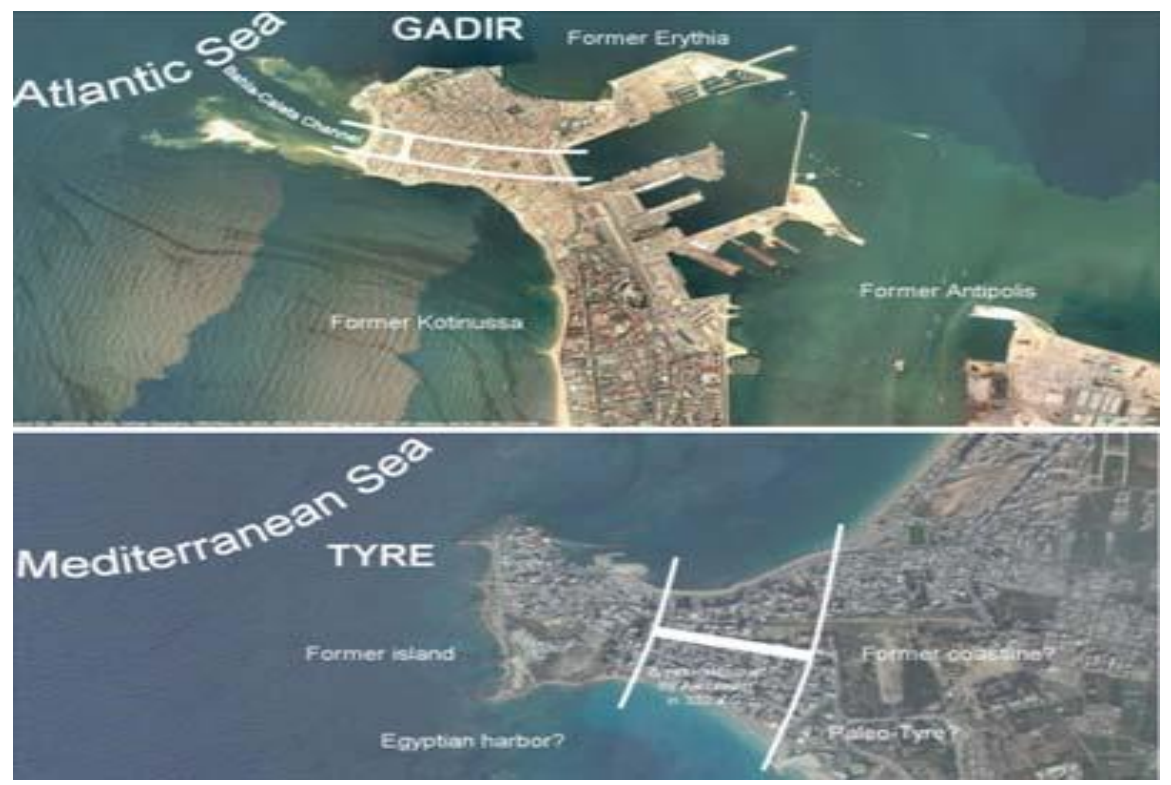

Fig. 1 - Comparativo entre Tiro (no Líbano) e Gádir (atual Cádis, na Espanha), nas imagens é possível perceber as características geomorfológicas preferidas pelos fenícios, ilhas próximas a costa com quebra-mares para proteção dos portos. Percebe-se as similaridades, nesse caso, entre o Extremo Oriente e o Extremo Ocidente na Antiguidade (Google Earth, 2014; Adaptado por Araújo de Lima, 2014).

O urbanismo das cidades fenício-púnicas arcaicas não seguia o plano ortogonal hipodâmico, em um primeiro momento as fundações herdaram o elemento orientalizante sem a influência helenística (Gonzáles Wagner, 2003: 53). A influência helenística aparece em tempos mais recentes (século VI a.C.), tal como em Cartago, onde a equipe arqueológica alemã 
interpretou o revestimento acentuadamente branco dos blocos que formavam a muralha como um padrão helenístico ${ }^{2}$.

É necessário traçar esse paralelo com a cultura helênica uma vez que o Mediterrâneo, um verdadeiro cimento líquido nas palavras de Michael Gras (1998), foi cenário de trocas materiais e de práticas culturais entre as culturas que se assentavam em suas margens.

Uma das evidências da amplitude da helenização ${ }^{3}$ extrapola a esfera cultural e se desenvolve espacialmente, como acontece na fundação, no século IV a.C., de uma casa da moeda em Cartago onde a economia passa a adquirir um caráter monetário (Tsirkin, 2000: 1235).

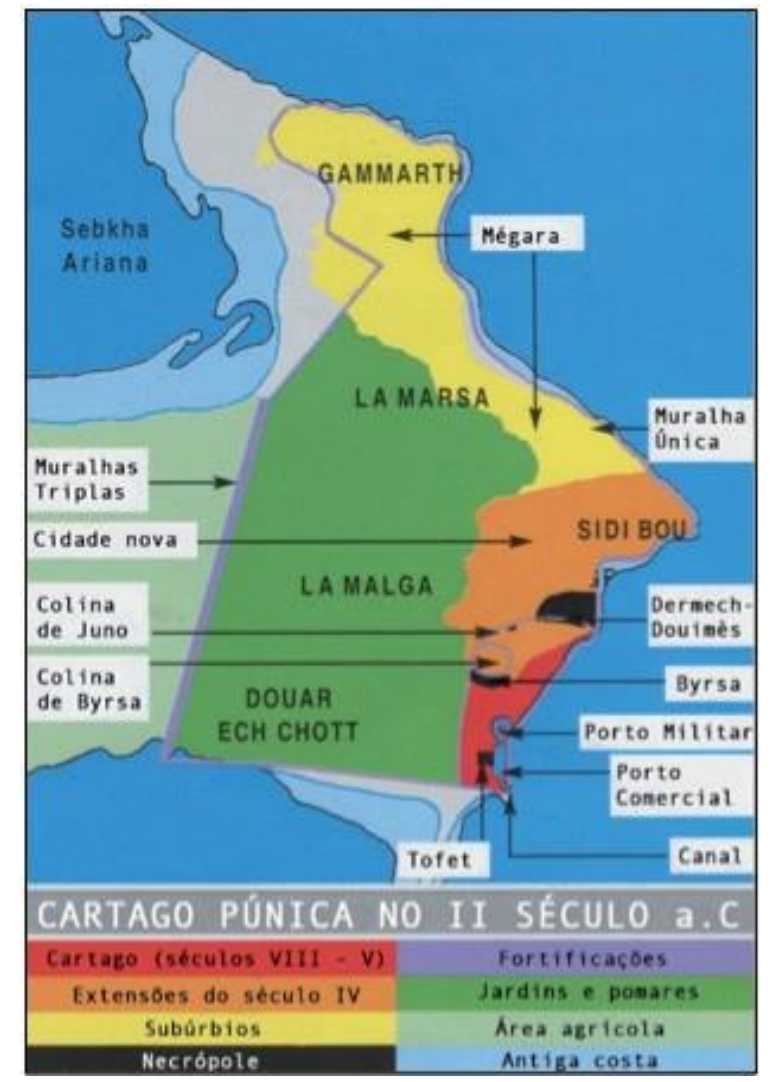

Fig. 2 - Cartago. Organização da cidade (Mahjoubi, 2002: 9).

\footnotetext{
2 Informações obtidas no site do LABECA, no banco de dados NAUSITOO, na cidade de Cartago.

${ }^{3}$ Tsirkin (2000: 1233) afirma que a problemática da helenização de Cartago se divide em duas abordagens distintas de investigação. A primeira, considera Cartago helenística do século IV ao II a.C. Já a segunda, em contrapartida, afirma que sua helenização foi superficial e não tocou a essência da civilização cartaginesa. Tsirkin, faz menção a uma aristocracia dominante familiar à cultura helênica, enquanto a massa popular e pelo menos uma parte da aristocracia sacerdotal continuavam com as tradições orientais.
} 
Sabemos que, ao chegarem em novas terras, os fenícios erguiam um templo, lbt em fenício, ato muito costumeiro, acontecendo em Nora (Sardenha), Gádir (Espanha), Lixos e Útica (África). Uma evidência material que atesta este ato se trata de estela monumental encontrada em Nora datada do século IX a.C. (Aubet, 2001: 206).

A reboque da questão espacial temos a questão da habitação feníciopúnica. Após a fundação, entramos em um momento lacunoso em que pouco se sabe sobre os assentamentos e sua organização, porém, provavelmente os abrigos seriam um dos elementos primeiros a partir da escolha de um assentamento em outras terras.

Após a construção de abrigos, teoricamente, o mesmo passa por diferentes momentos de sua existência. Podemos supor que durante a fundação, um abrigo mais rudimentar é erigido como habitação dos primeiros assentados quando a população se estabelece de fato garantindo acesso a recursos hídricos, agrícolas e minerais. Recebe, então, melhorias na sua configuração e também influências pelo contato com as populações autóctones. $\mathrm{O}$ momento último seria sua eventual decadência onde, em muitos casos no mundo fenício-púnico, temos vestígios geralmente escassos ${ }^{4}$, remanescem apenas como alicerces e em algum grau suas paredes.

Podemos supor através do alfabeto fenício que o termo que faz referência à casa possa ser a palavra bet, bt em fenício (Beyer, 2012: 113-116; Gianto, 2012: 31; Stanislav, 1997a: 176; Stanislav, 1997b: 60), termo muito similar a $l b t$, visto anteriormente, que designa templo ou santuário. Cada letra, no alfabeto fenício, também transmite o significado de uma palavra ${ }^{5}$.

Para alguns teóricos o nome dos sinais sempre se refere ao objeto original (Garbini, 1999: 118), algo que certamente ocorria, todavia não em todos os

\footnotetext{
${ }^{4}$ Há exceções de sítios em razoável estado de conservação como os sítios fenício-púnicos em contato com os nurágicos na Sardenha (Monte Sirai e Sulcis) e fenício-púnicos em contato com os líbios e berberes no Norte da África (Sabrata e Kerkouane da qual falaremos mais adiante).

${ }^{5}$ Para alguns teóricos, a influência egípcia sobre as cidades fenícias foi tão exponencial que o alfabeto fenício surgiu influenciado pelos hieróglifos e hieráticos egípcios, dada as suas inúmeras similaridades. A princípio, as primeiras letras de ambos os modos de escrita são representadas por uma cabeça de boi, a segunda por uma casa, a terceira pela imagem de um indivíduo e a quarta representando as ondas do mar. O Egito possuía uma série de sinais pictográficos limitados a consoantes. A representação gráfica de um leão por exemplo é, grosso modo, representada por arwe ou simplesmente $r w$. (Garbini, 1999: 103-106) O mesmo acontece no alfabeto fenício, as consoantes são utilizadas para a escrita de uma palavra. No árabe moderno, sendo um abjad, sistema de escrita que não possui vogais, a acentuação sobre uma letra indica a vogal que a acompanha na leitura. A acentuação porém, é apenas utilizada durante a educação básica da criança, depois são omitidas e é necessário o conhecimento prévio do leitor para reconhecer as vogais ocultas.
}

Revista Heródoto, Unifesp, Guarulhos, v. 02, n. 01, Maio, 2017. p. 323-345- 
casos. Assumindo essa teoria, o termo bétilo, traduzido como "morada de Deus", que faz referência às famosas pedras sagradas adoradas pelos fenícios (veremos adiante um exemplo dessas pedras na fig. 6), vem da união de dois termos semíticos bet e el ou il. Em fenício El pode tanto ser utilizado para identificar a divindade máxima do panteão fenício, o pai dos deuses, como também pode ser usado como termo genérico para se referir a uma deidade, sendo elat para o feminino e el para o masculino (Ribichini, 1999: 122).

Provavelmente o termo se conservou até nossos dias assumindo diferentes formas como no caso árabe بَيْ (trans: bayt) e no hebreu בית, (trans: bait), mantendo seu significado ${ }^{6}$.

O produto mais comum da arquitetura é, desde logo, a casa. Devido à sua ubiquidade é a forma geral mais particularizada e, sem embargo, a mais variável. Pode albergar uma pessoa ou várias famílias, pode ser feita de pedra ou madeira, barro, cimento ou metal, ou muitos materiais juntos incluindo papel, erva ou neve -. Os humanos criaram suas habitações nas covas de montanhas áridas e casas a base de peles de animais para transportar durante sua marcha. Usou-se grossas árvores como teto, ancorando suas casas a troncos vivos. A necessidade imperativa de alojamento em qualquer condição, desde as geleiras polares, quase tão mortas como a lua, até as pródigas terras mediterrânicas, originou o aproveitamento de qualquer meio de construção. A casa, portanto, foi a escola básica do construtor ${ }^{7}$ (Langer, 1953: $92-99$ apud Patteta, 1984: 39$40)$.

Com referência ao arejamento e iluminação das casas fenício-púnicas, sobre a dimensão e características da janela, a altura dos edifícios e o número de andares, pouquíssimo pode ser descrito uma vez que os pisos superiores, geralmente, são os primeiros a cair devido a fatores ambientais ou culturais.

Por outro lado, consegue-se uma descrição com maior nível de detalhes nos pisos inferiores, graças a sobrevivência de alguns vestígios material, na maior parte das vezes remanescentes cerâmicos.

Tratar, pois, da casa fenício-púnica, torna-se uma tarefa que requer primeiramente entender questões relacionadas à identidade e às práticas culturais híbridas (Bhabha, 1994). O conceito de colônia que iremos

\footnotetext{
${ }^{6}$ No caso hebraico é comum, até os nossos dias, a utilização religiosa do termo por muitas sinagogas que o usam como parte de seu nome, sendo também comum para se referir a escolas, sem perder a sua tradução original.

7 Todas as traduções de autores estrangeiros são de nossa autoria.
} 
aplicar nesse estudo não é o mesmo ao processo colonial moderno que ocorreu em África, Ásia, América e Oceania uma vez que se deu uma profunda exploração econômica nessas localidades. Para o mundo antigo, é necessário compreender que a conceituação referente às colônias se dá de forma diferente da empreendida na modernidade (Van Dommelen, 2005: 110).

Para o caso fenício, o estabelecimento de uma colônia não implicava na submissão dessa perante sua cidade-mãe, existia um comércio que não era sujeito a regras impostas por um "colonizador" como em tempos mais recentes da História.

Em outras regiões da Bacia Mediterrânica, os fenícios entraram em contato com diversas populações, como os tartésicos, iberos, berberes, gregos e nurágicos dentre outras.

A ilha de Ibiza, Iboshim em fenício, por exemplo, foi inicialmente a única das ilhas Baleares que presenciou a fundação de assentamentos fenícios e púnicos diferentemente das ilhas Maiorca e Minorca que foram habitadas pelos povos talaióticos durante a Idade do Bronze. Formentera permaneceu inabitada devido a falta recursos hídricos. (Van Dommelen, 2005: 130-131).

Desses encontros ocorridos ao longo da Bacia do Mediterrâneo se desenvolveram práticas híbridas em diferentes aspectos na vida no assentamento tais como a utilização de técnicas de construção para as casas mantendo algumas especificidades vindas do Levante, sincretismo religioso com adoção ou assimilação de deuses, entre outras atividades.

Portanto é necessário ponderar a respeito da dualidade que vigorou durante muito tempo dividindo o mundo colonial entre colonizador e colonizado e perceber que o contato não criou uma sociedade dividida entre dominadores e dominado. Nessa oposição em preto e branco não se enxerga os mais diversos tons de cinza das ações individuais (Van Dommelen, 2005: 116).

O conceito de hibridismo traz à luz as ações individuais que por muito tempo foram ignoradas durante muito tempo pelas fontes epigráficas.

Entre fenícios e autóctones, um leque de ações individuais pode ter se desenrolado pelas mais diversas camadas sociais, seja pela adoção da cerâmica levantina, pelas relações sociais que se desenvolviam entre autóctones e fenícios que ora poderiam apoiar a presença estrangeira legitimando-a e adotando suas práticas ou repeli-la em nome da manutenção de sua identidade. 
Como existem poucas fontes textuais fenício-púnicas a respeito da organização dessa sociedade, a Arqueologia vem trabalhando no entendimento do pensamento dos antigos estudando os sítios arqueológicos que muito podem corroborar no estudo dos contatos na Antiguidade. Um valioso exemplo são os sítios de ambientes domésticos que podem revelar detalhes importantes de como o fenício pensava o mundo ao seu redor e as relações das quais ele fazia parte e também desenvolvia. Dessa forma, auxilia no entendimento de uma sociedade. Mortimer Wheeler nos relembra que "o arqueólogo, portanto, escava pessoas, não coisas". (1954: v)

Assim, seguirão alguns exemplos sobre o ambiente doméstico feníciopúnico pela Bacia do Mediterrâneo. Tomaremos o Levante como primeiro caso a ser estudado, sendo o ponto de origem e de expansão da civilização fenícia.

\section{Levante}

\section{Tiro}

Antes de aprofundar no ambiente doméstico, é necessário compreender o contexto histórico fenício-púnico. A Fenícia recebeu, durante um longo tempo, forte influência egípcia, gentes com as quais os fenícios faziam um lucrativo comércio.

A procura por cedro por parte dos egípcios era insaciável (Markoe, 2000: 19). Muito utilizado em acabamentos graças à sua durabilidade e fragrância, fato que tornou o cedro não apenas utilizado na construção de embarcações, mas também em templos, como vigas de telhados, santuários portáteis e altares, igualmente era muito utilizado também pela indústria funerária para o fabrico de caixões para a elite e para a classe sacerdotal (Markoe, 2000: 19).

Tiro foi uma cidade comercial e marítima par excellence segundo Aubet (2001: 31). Também conhecida como Sor, que significa rocha, foi unida ao continente por um molhe (ver fig.1) construído por Alexandre, o Grande em 332 a.C. (Ramazzina, 2012: 168).

Ainda conforme Ramazzina (2012: 169), o assentamento, antes do assédio de Alexandre, o Grande, desenvolveu-se parte na ilha e outra parte em terra-firme (ver fig. 1). Ushu segundo as fontes egípcias e assírias e Paleotiro (ou Antiga Tiro) segundo fontes clássicas. Todavia não há consenso entre os pesquisadores sobre a exata posição. 
Dos séculos XX ao XVIII a.C., as cidades da Fenícia floresceram com o comércio durante o Médio Império Egípcio e muitos dos aspectos de vida dos egípcios foi incorporado ao modo de vida dos fenícios ${ }^{8}$. A evidência dessas trocas pode ser percebida pelas tumbas de certos reis, decoradas com medalhões, peitorais, coroas, cetros de ouro em estilo egípcio. A influência egípcia foi tão exponencial que existia um templo egípcio na cidade. Do lado egípcio, também existiu influências vindas do Levante, no mito de Ísis, a deusa passa por Biblos procurando o corpo de Osíris lançado no mar, dentro de uma caixa, por Seth (Bondì, 1999: 25).

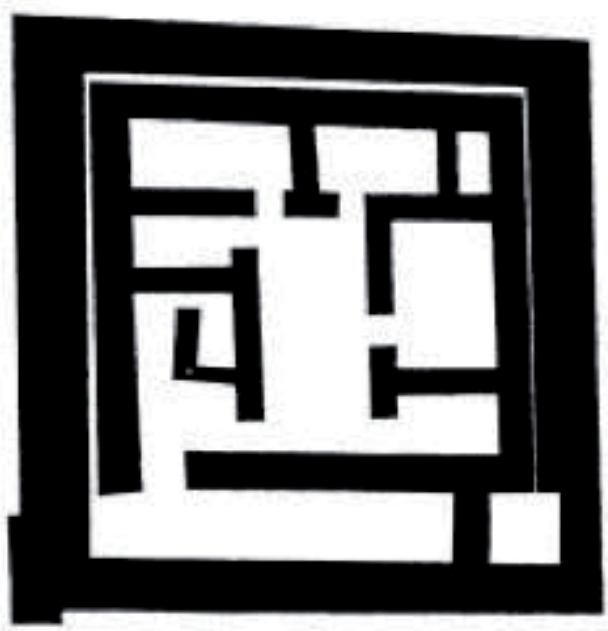

Fig. 3 - Planta da casa fortificada de Horvat Rosh Zayit, Israel (Markoe, 2000: 72).

Segundo Markoe (2000), a típica casa fenícia no início da Idade do Ferro (ca. 1200-500 a.C.) consistia em três ou quatro cômodos arranjados de várias formas diferentes, frequentemente um longo corredor providenciava o acesso a dois ou algumas vezes três quartos adjacentes de tamanhos iguais. Markoe afirma que em Horvat Rosh Zayit (ver fig.3) as habitações de três ou quatro quartos eram as formas de casa dominante na antiga Israel.

A investigação arqueológica em dois locais díspares esclarece aspectos do projeto da casa fenícia e sua construção. Em Horvat Rosh Zayit a Baixa Galileia, as escavações descobriram a residência fortificado de um comerciante fenício. No espaço térreo, o edifício consistia em um salão central, rodeado por oito salas de tamanho variado, que serviram como instalações

\footnotetext{
${ }^{8}$ Existia um porto egípcio ao sul da ilha de Tiro (ver fig. 1).
} 
de armazenamento. (Todo o complexo continha ao todo trezentas jarras de armazenagem). Originalmente, o complexo contava com dois andares, seus limites superiores eram marcados por limiares de pedra na parede. Todo edifício foi cercado por um grande muro, com quatro torres nos cantos. Esta estrutura singular, pode ser datada de meados do século $X$ a.C. até a metade do séculos IX a.C., esse sítio oferece uma rara visão do início da antiga habitação fenícia na Idade do Ferro. (Markoe, 2000: 71)

Entender a organização espacial da casa fenícia no Levante será o primeiro passo para avançar em nossa discussão. Tomaremos esta como base da constituição do ambiente doméstico nos demais assentamentos fenício-púnicos no Mediterrâneo.

Através de fontes assírias, como nos relevos de Senaqueribe, podemos notar que o quarteirão residencial ficava dentro das muralhas e as casas amontoavam-se umas sobre as outras. As habitações tinham vários andares de altura e possuíam toques elegantes, colunas estavam dispostas em ambos os lados das portas da frente e as janelas do piso superior possuíam balaustradas com ornamentos na decoração (Bondì, 1999, 318).

Sobre a decoração doméstica, o geógrafo grego Estrabão (XVI, II, 23), escreveu que as casas de Tiro e Arado possuíam, como foi citado anteriormente, muitos andares de altura a mais que as romanas.

\section{Península Ibérica}

\section{Gádir}

Em Gádir, assentamento fenício fundado nas Colunas de Héracles/Melqart, pode-se observar a partir de uma abrangente rede de bacias hidrográficas a localização de diversos assentamentos semíticos e a localização estratégica gaditana no estuário do Rio Guadalquivir.

No Extremo Ocidente, a extração de prata ao longo das bacias hídricas da região determinou a localização dos assentamentos semíticos. $\mathrm{Na}$ Península Ibérica muitos assentamentos se localizavam, em um primeiro momento, nas proximidades ou às margens de rios, formando uma verdadeira rede dendrítica, sobre à qual falaremos adiante, para o escoamento da prata, que junto com a argila, terra e calcário são as matérias-primas mais frequentes (Díes Cusí, 2001: 80). 
Tomando como base a teoria do lugar central produzidas por Walter Christaller (1966), entende-se por rede dendrítica um tipo de organização urbana. Posteriormente, Kelley (1985: 233-53) afirma que a organização de uma rede dendrítrica consiste em um centro urbano primaz localizado estrategicamente em estuário de uma rede hidrográfica alimentado por outros pequenos centros espalhados na hinterlândia dessa rede que realizam a extração das riquezas, no caso dos fenícios na Espanha, a prata.

É importante salientar, para evitar uma comparação anacrônica, que as preocupações de Christaller voltavam-se para aspectos da Modernidade, todavia há elementos que podem ser pensados para a Antiguidade para se entender o processo de formação de assentamentos humanos.

Sobre as construções, de acordo com Zamora López (et. al., 2010: 205), após as escavações realizadas no subsolo do teatro Cômico de Cádiz, foram identificados quatro períodos estratigráficos:

I) Século IX a 820/800 a.C, comportando a chegada dos fenícios e algumas das suas construções iniciais, provavelmente para extração do púrpura uma vez que foi encontrada uma massa compacta de cor púrpura formada por argila e moluscos da espécie Murex Trunculariopsis Trunculus;

II) Cerca de 820/800 até 720 a.C., desenvolvem-se unidades domésticas (fig. 5), nas palavras dos autores "vivendas", onde os edifícios desciam a encosta até o canal da Bahía-Caleta (ver fig. 1). Vale ressaltar que nesse período surgem os primeiros testemunhos dos usos domésticos das habitações, como o descobrimento de fornos tipo tannur (conhecido também pelo nome de tandoor), forno feito em forma de ânfora de barro usado no fabrico de pães. (ver fig. 4)

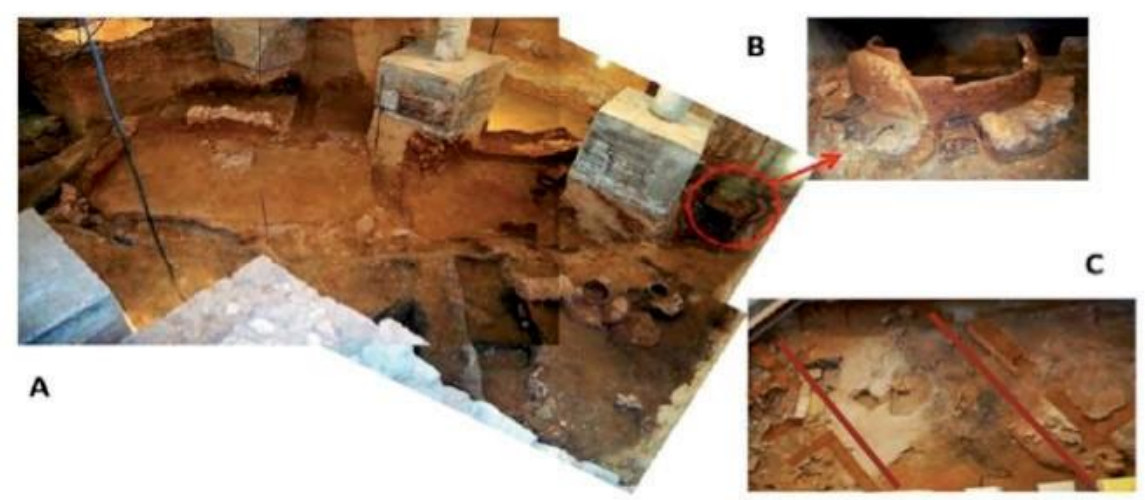

Fig. 4 - Vista do II período: (A) Grupo Estrutural; (B) Forno do tipo tannur; (C) Rua entre o primeiro grupo estrutural e o segundo (Zamora López, et. al., 2010: 207). 
III) No final do VIII ao início do VI a.C., ocorre o abandono dos grupos estruturais, quando os autores afirmam que possivelmente ocorreu alguma catástrofe natural pela recuperação de um cadáver entre escombros sem os ritos de enterramento. $\mathrm{O}$ cadáver pertencia a um indivíduo adulto (25-30 anos) falecido in situ. Foi encontrado em posição de defesa e sua morte foi interpretada por asfixia provavelmente proveniente por incêndio. $\mathrm{O}$ corpo pereceu abaixo de uma fina camada de areia de proveniência eólica com manchas de cinzas sobre a superfície que aumentam em número e intensidade mais a norte.

Os pesquisadores acreditam que o indivíduo pode ter conseguido escapar do fogo cujo o foco se concentrava na zona de escavação abaixo do Teatro Cômico, mas que não resistiu devido os sintomas da intoxicação. Segundo o Dr. Manuel Calero (Zamora López et. al., 2010: 209) o indivíduo pouco antes de morrer fraturou o colo do fémur por um traumatismo de alta energia possivelmente de uma queda.

Após a catástrofe o edifício ruiu e outro foi edificado. A arquitetura antiga foi substituída por alvenaria e surge a sustentação dos pilares na técnica de construção conhecida como Opus Africanum ${ }^{9}$, esse novo edifício se constituía de cinco cômodos, sendo o maior de 16,54 $\mathrm{m}^{2}$ com um pilar central de adobe e um banco corrido apoiado à parede; IV)

No segundo e terceiro trimestre do século VI a.C., as estruturas, infelizmente, foram muito afetadas pelas construções da época romana, sendo que se conservam apenas os muros de fachada e um umbral calçado de conchas de várias espécies (Zamora López et.al., 2010: 205210).

As técnicas de construção fenícias foram integradas e reinterpretadas pela sociedade tartésica da Península Ibérica. Tiro de acordo com a tese de Díes Cusí (2001: 90) não teria capacidade militar e nem econômica suficiente para subjugar a população autóctone e garantir controle direto sobre as minas de prata a mais de 4.000 quilômetros do Levante.

\footnotetext{
${ }^{9}$ A técnica de construção Opus Africanum é uma variante de uma outra técnica utilizada pelos fenícios na Idade do Ferro (Markoe, 2000: 72). A Opus Africanum baseia-se na construção de cadeias de grandes blocos dispostos na vertical onde blocos menores alternam de forma horizontal. Esse tipo de técnica construtiva foi muito difundida em Cartago devido à escassez de árvores para a sustentação do edifício. A técnica foi difundida para o mundo fenício-púnico. Infelizmente poucos monumentos com exemplares dessa técnica se conservaram em Cartago. Depois da destruição de Cartago, os romanos adotaram a técnica local de construção e tornou o Opus Africanum uma técnica de construção exclusiva e padrão para aquela parte do mundo (Adam, 1994: 233).
} 
Na opinião de Díes Cusí, os fenícios provavelmente se associaram às classes dominantes estabelecendo uma série de pactos com esta. Dessa associação uma série de costumes orientas foi assimilada. Este fato pode ser observado nas orientalização dos ritos adotados pelos príncipes tartésicos. A aristocracia tartésica garantia acesso aos recursos minerais e agrícolas por meio de um sistema de trocas onde os fenícios produziam artigos de luxo para os príncipes autóctones que decoravam suas tumbas com marfim, ouro, vasos de prata e bronze, feito para eles nas oficinas de Gádir.

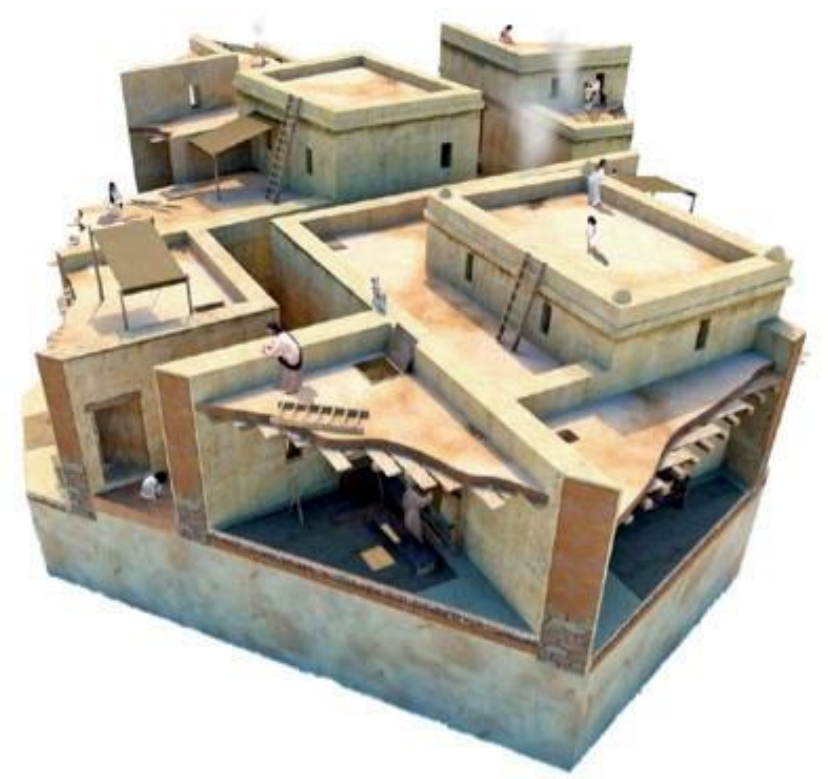

Fig. 5 - Reconstrução do II período, vista da construção de alvenaria e revestimento de adobe (Zamora López, 2010: 209).

As habitações tártesicas, geralmente revestidas de barro, construídas em formato ovoide ou circular com paredes assentadas em uma base de laje, adotaram do Oriente a prática de construir em uma planta quadrangular e utilizar um revestimento mais elaborado na cobertura das superfície das estruturas (Díes Cusí, 2001: 92).

\section{Sicília}

\section{Solunto}

Os estudos espaciais vêm avançando também no Brasil com a criação do Laboratório de Estudos sobre a Cidade Antiga (LABECA), voltado para os estudos do Mediterrâneo Antigo no Museu de Arqueologia e Etnologia da Universidade de São Paulo (MAE-USP). 
Através do banco de cidades, denominado Nausitoo, o laboratório tem como objetivo compreender a formação das cidades antigas, gregas, autóctones e fenício-púnicas. Pelas expedições arqueológicas realizadas na Sicília grega e fenícia coletou-se material que visa entender a organização das cidades da antiguidade auxiliando também no entendimento das habitações antigas.

Para Kormikiari (2012), professora do MAE-USP e pesquisadora do LABECA, a importância dos estudos sobre a espacialidade fenício-púnica foram durante muito tempo marcados por uma visão preconceituosa baseada na história que se fazia nos séculos XVIII e XIX, a qual associava cada povo a uma identidade, reservando à cultura fenícia o "carimbo" de um povo comerciante. Esse "carimbo" como cita a autora (2012: 144), quase que descaracteriza a existência até mesmo de cidades fenícias complexas e bem estruturadas. Uma vez que as fontes textuais são escassas, conduz irremediavelmente os desconhecedores à uma visão preconceituosa e vaga.

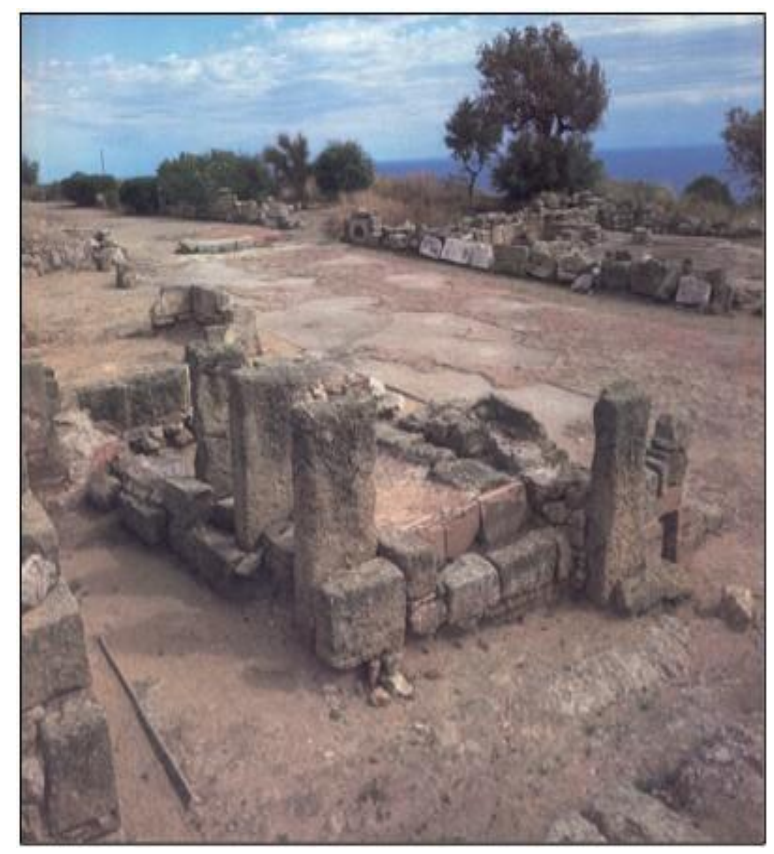

Fig. 6 - Edifício sagrado com três bétilos (Acervo do Labeca, 2005).

Em Solunto podemos encontrar elementos fenício-púnicos como cabeças de terracota com símbolos púnicos. $\mathrm{Na}$ rua principal, onde estão os edifícios públicos, há um altar com três bétilos (pedras sagradas) que são símbolos da religião fenício-púnica (Fig.6). Julgando pelos remanescentes encontrados nos pés do altar, animais eram sacrificados ali (Tusa, 1999: 240). 
De acordo com Tucídides, Solunto foi fundada em território fenício, no norte da Sicília. Os vestígios arqueológicos até agora mostram uma cidade do século IV a.C. e apenas as necrópoles são do século VI a.C. Foi saqueada por Dionísio de Siracusa em 368 a.C., e em seguida reconstruída. Pelo que se sabe viveu sempre na órbita de Siracusa, inclusive durante o período timoleonteo. A partir da II Guerra Púnica, na segunda metade do século III a.C., Solunto passou para a órbita romana. Solunto está localizada no litoral norte da Sicília a 20 km a leste de Palermo. (...) Em torno da metade do século IV a.C. a arqueologia comprova que Solunto foi totalmente reorganizada urbanisticamente.

(Labeca: http://labeca.mae.usp.br/pt-br/city/78/)

Vestígios datados demonstram na cidade, todavia, que o elemento púnico estava presente não apenas em objetos como também em edifícios religiosos, estes que representam o espírito dos habitantes da cidade (Tusa, 1999: 240).

\section{Norte da África}

\section{Cartago}

Segundo Markoe (2000: 72), as escavações em Byrsa, em Cartago, provaram a continuação de uma antiga prática oriental onde nas fundações de um edifício depositava-se uma oferenda ao sagrado.

Ainda segundo Markoe, a prática foi documentada por duas vezes em Byrsa e se dividia em duas fases, a primeira onde uma lamparina de argila era depositada junto a uma tigela de cerâmica artesanal na área central da habitação, e, em um segundo momento, uma jarra de cerâmica era intencionalmente quebrada e seus restos eram depositados debaixo do chão. Sendo Cartago uma colônia tíria, esse ritual segundo o autor, provava a profunda relação entre o assentamento e sua cidade-mãe sendo esse rito costumeiro no Levante.

A típica casa fenício-púnica, dessa forma, representaria o tipo urbano do Levante, consistindo em um edifício retangular com um grande pátio fechado e uma série de quatro quartos separados ao longo de sua extensão (Markoe, 2000: 71). A construção era feita de paredes de tijolos e tinha fundações de pedra, as escavações em Byrsa revelaram que o tipo Opus Africanum, citado anteriormente, já estava presente no período 
tardio em Cartago (fig. 7).

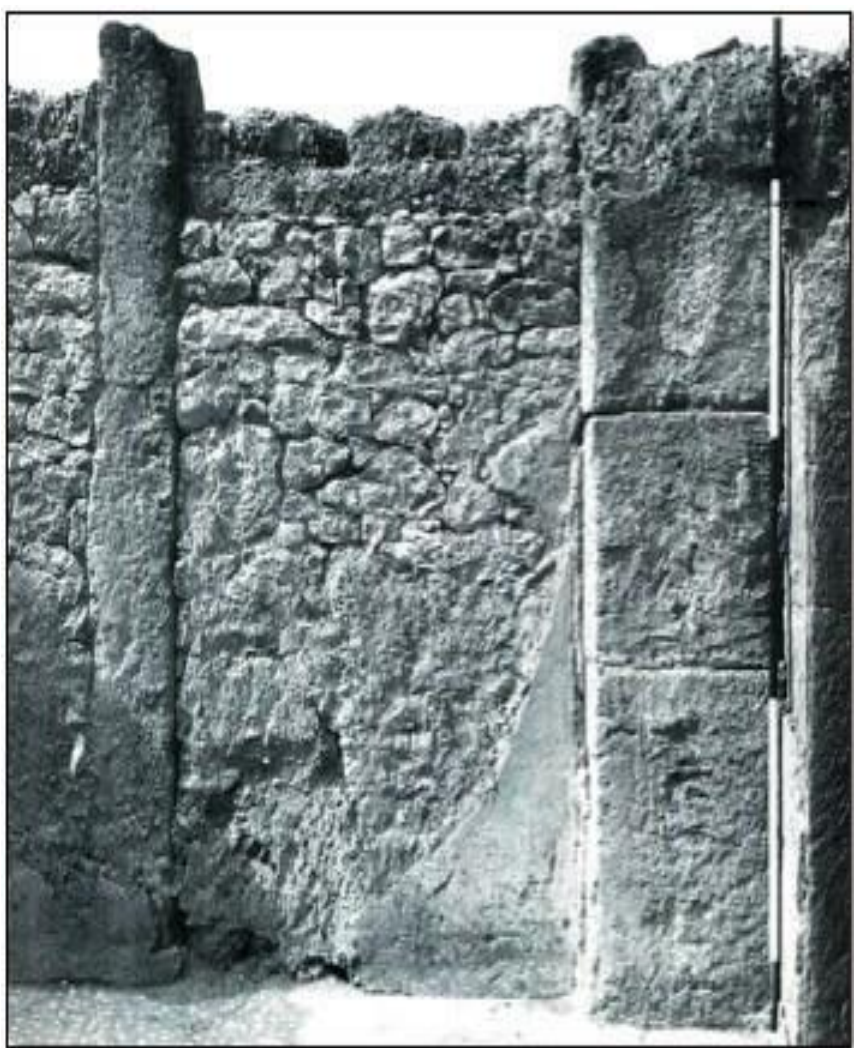

Fig. 7 - Opus Africanum no quarteirão púnico do período tardio na colina de Byrsa, percebe-se os grandes blocos dispostos na vertical e entre as estruturas posicionam-se blocos menores na horizontal (Krings, 1995: 23).

O pátio, a fonte primária de luz e ar, formava o coração das atividades domésticas na casa púnica, assim como tinha configurações de um espaço privado e isolado, seus pórticos com colunas garantiam acesso direto às principais câmaras da casa, incluindo o seu salão principal, quartos, e despensas... Quase todos os pátios possuíam, como característica central, um poço escavado ou um implúvio para a recepção das águas pluviais. (...) As casas mais abastadas tinham banheiros privados equipados com banheiras rebocadas. (...) Todas as casas púnicas, grandes e pequenas, foram equipadas com algum tipo de instalação de cozinha, muitas vezes reconhecível pela pedra ou por um anel de terracota que formava a lareira definindo seu canto. (...) Cômodos localizados na entrada da casa podem ter funcionado como lojas ou quartos comerciais (Markoe, 2000: 73-74).

Picard afirma que Cartago, nos últimos anos de sua independência, antes de sua destruição e reconstrução por Roma, recebeu aperfeiçoamentos na 
sua organização urbana. Na colina de Byrsa, foram descobertas habitações providas de esgoto, os desníveis das ruas foram corrigidos por escadas que levavam ao templo de Eshmum no cume do declive (Picard, 1958: 49).

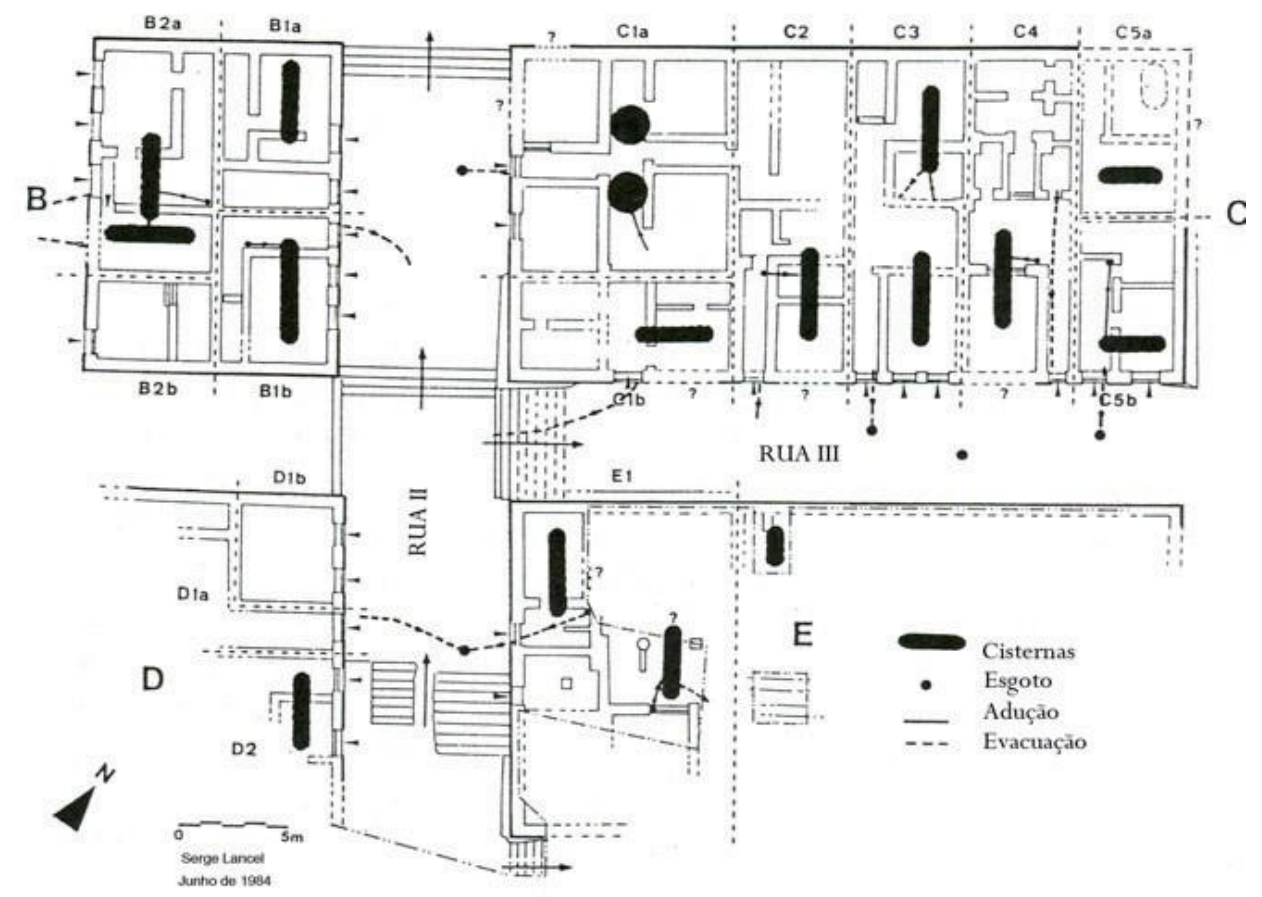

Fig. 8 - Quarteirão púnico do período tardio na vertente sul de Byrsa (Krings, 1995: 405).

Em outro trecho, Picard afirma que "com suas casas simples, caiadas (pintadas com cal), cobertas de terraços ou de cúpulas, as suas ruelas estreitas e tortuosas, Cartago devia parecer-se muito com as cidades da moderna Tunísia" (1958: 50, 57).

Para alguns teóricos, a casa púnica, não se abria muito para a rua como as romanas (Picard, 1958: 50; Díes Cusí, 2001: 85).

Alguns autores argumentam que dos séculos IV ao II a.C, as elites cartaginesas receberam influência grega. Para Tsirkin (2000: 1233), a influência helenizante respondia aos gostos da maior parte da aristocracia, enquanto camadas populares continuaram com suas tradições orientais. Tsirkin afirma que:

Ela se manifestou só na vida da aristocracia e pelo visto na vida dos artistas e artesãos que a serviam. Tanto a massa popular como certos círculos mais conservadores da nobreza seguiam suas velhas tradições e o anterior modo de viver (...) Pode-se 
dizer que em Cartago, assim como no Oriente e em Roma, surge uma cultura do tipo helenístico, com algumas particularidades que a distingue da oriental helenística e da romano-helenística (Tsirkin, 2000: 1235).

As casas eram de uma organização muito simples segundo Picard, tendo compartimentos quadrados ou retangulares justapostos sem uma preocupação com a arquitetura. $\mathrm{O}$ autor chega a supor que as casas em Byrsa de altura considerável seriam divididas em vários pisos possivelmente para aluguel. (Picard, 1958: 51).

O revestimento sobre o solo era feito com cimento pintado pelo pó vermelho dos tijolos, onde se espalhavam pedaços de mármore branco, tal tipo de pavimentação era conhecida pelos romanos como "pavimento púnico".

\section{Kerkouane}

De todo o mundo púnico, Kerkouane é a cidade melhor preservada uma vez que foi abandonada no século III a.C., e não foi mais reconstruída, sendo de fato uma cidade púnica do Período Helenístico. Kerkouane é onde se tem uma melhor ideia dos aspectos domésticos púnicos, uma vez que se identificou a existência de casas com banheiras próprias, sistemas de canalização e decorações entalhadas ou pintadas nos remanescentes das colunas dos pórticos (Fantar, 1988: 211). 


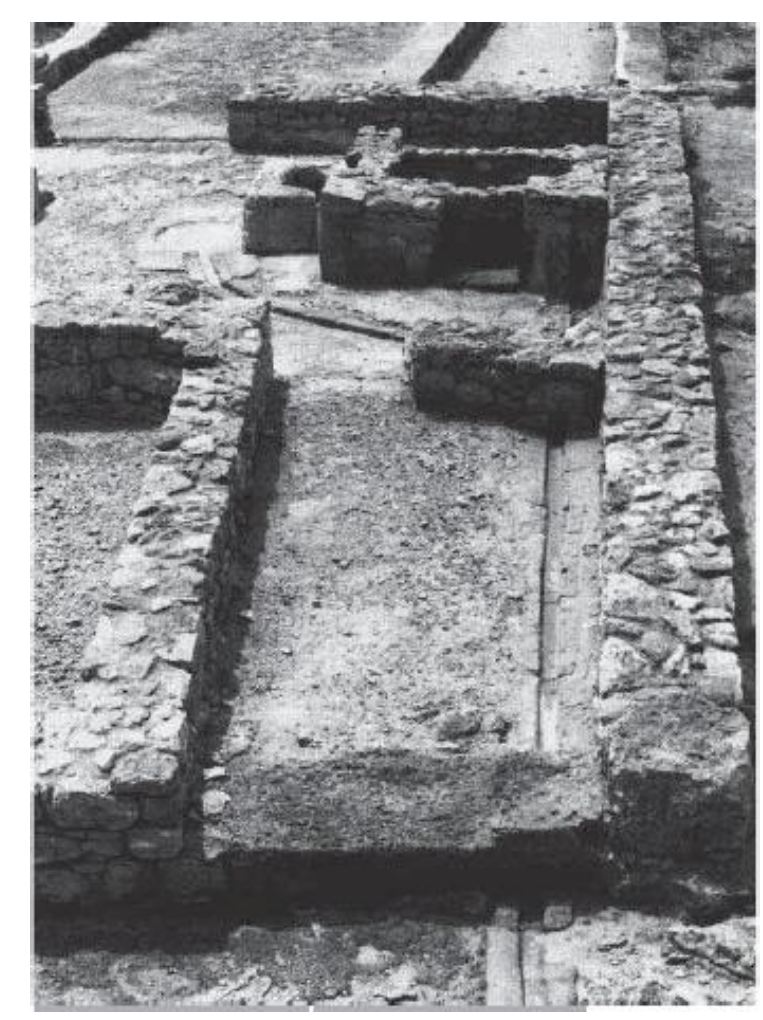

Fig. 9 - Sistema de esgoto (Fantar, 2005, 4171, fig.5)

Além de possuir as grandes casas, como em Cartago, que possuíam em seu interior um pátio fechado, as habitações em Kerkouane seguiam também o estilo de casas geminadas ${ }^{10}$ alinhadas à rua, muito comum também era a imagem do signo de Tanit no chão da residência (Fantar, 1999: 211; Mezzolani, 2000: 1224).

Mezzolani (2000: 1226) se refere ao caso das casas helenísticas de Solunto devido a sua semelhança planimétrica e afirma que, devido ao conjunto do banheiro e cozinha, há correspondência com as casas de Olinto. Para o autor a partilha do espaço doméstico poderia expressar os laços de parentesco, que permitia a utilização dos espaços comunitários como o pátio, mas que também assegurava a vida privada graças à separação dos ambientes (Idem, 2000: 1266).

Mezzolani afirma que a presença de vários banheiros poderia ser uma possível reflexo da existência de mais de um núcleo familiar, para corroborar esta teoria, a existência de várias escadas dentro da casa pode ser um indício de uma pluralidade de famílias uma vez que as escadas se localizavam ou no corredor da casa ou no pátio. No caso das casas de

\footnotetext{
10 Segundo Fantar (1999: 211) trata-se de um estilo originalmente líbico. Nesse tipo de organização as casas dividiam entre si apenas uma parede.
}

Revista Heródoto, Unifesp, Guarulhos, v. 02, n. 01, Maio, 2017. p. 323-345- 
Kerkouane, portanto, é possível pensar na hipótese de uma entrada comum que garantia acesso a uma unidade habitativa.

\section{Considerações finais}

Desde o princípio, o objetivo deste estudo foi traçar um panorama da casa fenício-púnica a fim de demonstrar as mudanças ocorridas no ambiente doméstico através da variação das práticas de construção. Fato que ora poderia pender para o lado do "colonizado" como também poderia pender para o "colonizador". Assim os encontros coloniais devem ser entendidos como trocas de ideologia entre seres humanos, sem a necessidade de mensurar o grau de assimilação de ambas as partes, mas reconhecendo que o "dominador" pode receber influências do "dominado" e uma cultura não anula a totalidade da outra, mas juntas concebem práticas híbridas (Van Dommelen, 2005).

O panorama levantado nesse artigo sobre os sítios estudados visa reconhecer os momentos das estruturas habitacionais fenícias iniciais em quatro localidades nesse estudo no; I) Oriente, pelo estudo da arquitetura fenícia em sua origem; II) Ocidente reconhecendo o contato fenícioautóctone e suas influências no sul da Península Ibérica, III) Na Sicília, onde é possível perceber um momento helenístico pelo contato dos fenícios com os gregos em algumas localidades, como no caso da estudada Solunto; IV) No Norte da África, onde é possível caracterizar a arquitetura púnica pela existência de pátios, sistemas eficientes de ventilação e iluminação natural, abastecimento de água pelas chuvas e vestígios de banheiras individuais.

Por fim, esquadrinhamos nesse artigo uma origem em comum referente à habitação fenício-púnica, quais foram as técnicas compartilhadas entre fenícios e autóctones pela Bacia do Mediterrâneo. Buscou-se entender os padrões que se desenvolveram na arquitetura fenício-púnica e suas ramificações no decorrer do contato com os povos autóctones para obter os resultados das práticas híbridas e únicas que variam de região para região.

A arquitetura como um feito plástico tende a ser por muitas vezes pensada e transformada para a resolução de uma função, entendendo função como a sua simples utilidade e, no caso das casas, também conforto. Urbanística e arquitetura são os documentos mais reveladores, sendo um reflexo fiel de uma sociedade (Le Corbusier, 1923: 27-28 apud Patteta, 1984: 27-28). 


\section{Referências bibliográficas}

ADAM, Jean-Pierre. Roman Building: Materials and Techniques. Bloomington: Indiana University Press, 1994.

AUBET, Maria Eugenia. The Phoenicians and the West. Politics, Colonies and Trade. Tradução: Mary Turton Cambridge: University Press, 2001.

BEYER, Klaus. The languages of Transjordan. In: GZELLA, Holger (ed.), Languages from the World of the Bible. Boston-Berlin: Walter de Gruyter, 2012, p. 111-117.

BABHA, Homi. The Postcolonial and Postmodern. In: BABHA, Homi. The Location of Culture. London; New York: Routledge, 1994, p. 171-197.

BONDI, Sandro Filippo. City Planning and architecture. In: MOSCATI, Sabatino (ed.), The Phoenicians. New York: Rizzoli, 1999, p. 311-348.

BONDI, Sandro Filippo. The Origins in the East. In: MOSCATI, Sabatino (ed.), The Phoenicians. New York: Rizzoli, 1999, p. 23-29.

CHRISTALLER, Walter. Central places in Southern Germany. Tradução: Carlisle Baskin. Prentice Hall: New Jersey, 1966.

DÍES CUSÍ, Enrique. La influencia de la arquitectura fenicia en las arquitecturas indígenas de la Península Ibérica (S. VIII-VI). In: MATA, Diego Ruiz; CELESTINO PÉREZ, Sebastián (eds.), Arquitectura oriental y orientalizante en la Península Ibérica. Madrid: Consejo Superior de Investigaciones Científicas, 2001, p. 69-122.

ESTRABÃO. Geography. Tradução: Horace Leonard Jones. Harvard University Press: Cambridge, vol. 8, 1932.

FANTAR, Muhammad. North Africa. In: MOSCATI, Sabatino. The Phoenicians. New York: Rizzoli, 1999, p. 199-230.

FEBVRE, Lucien; BATAILLON, Lionel. A Geographical Introduction to History. Tradução: MOUNTFORD, Eleanor, New York: Alfred Knopf, 1925.

GARBINI, Giovanni. The Question of the Alphabet. In: MOSCATI, Sabatino. The Phoenicians. New York: Rizzoli, 1999, p. 101-119.

GIANTO, Agustinus. Ugaritic. In: GZELLA, Holger (ed.), Languages from the World of the Bible. Boston-Berlin: Walter de Gruyter, 2012, p.28-52. 
GONZÁLES WAGNER, Carlos. El urbanismo fenício de época arcaica y su impacto en las sociedades autóctonas. In: CASTRO, José Luis López. Las ciudades fenicio-púnicas en El Mediterráneo Occidental. Editorial Universidad de Almería: Almería, 2003.

GONZÁLES PRAT, Alfredo. Arquitectura orientalizante en el Levante peninsular. In: MATA, Diego Ruiz; CELESTINO PÉREZ, Sebastián (eds.), Arquitetura oriental y orientalizante en la Península Ibérica. Madrid: Consejo Superior de Investigaciones Científicas, 2001, p. 173-191.

GRAS, Michel. O Mediterrâneo Arcaico. Teorema: Lisboa, 1998.

KORMIKIARI, Maria Cristina Nicolau. Expansão marítima e influência cultural fenícia no Mediterrâneo centro ocidental. Belo Horizonte: Clássica, V.5/6, supl.2, 1992, p. 261-267.

KELLEY, Klara Bonsack. Dendritic Central Place Systems and the Regional Organization of Navajo Posts. In: SMITH, Carol. (org.), Regional Analysis, v. 1, Economic Systems. New York: Academic Press, 1985, p. 219-254.

KORMIKIARI, Maria Cristina Nicolau. O Conceito de cidade no mundo antigo e seu significado para o Norte da África Berbere. In: HIRATA, Elaine Farias Veloso; FLORENZANO, Maria Beatriz Borba (orgs.), Estudo sobre a Cidade Antiga. São Paulo: Editora da Universidade de São Paulo/FAPESP, 2009, p. 137-172.

KORMIKIARI, Maria Cristina Nicolau. A movimentação fenício-púnica no Mediterrâneo ocidental: Novas perspectivas a partir dos estudos arqueológicos da paisagem. In: Mare Nostrum, 3, 2012, pp. 1-19.

KORMIKIARI, Maria Cristina Nicolau. O mundo fenício-púnico sob uma nova perspectiva: o uso da terra em terras colonizadas. In: XIX Congresso da Sociedade Brasileira de Estudos Clássicos. I Simpósio Luso-Brasileiro de Estudos Clássicos, 2013, Brasília: Universidade de Brasília, 2013.

KRINGS, Véronique (ed.). La civilisation phénicienne et punique. Manuel de recherche. Leiden-New York : Brill, 1995.

CASTRO, José Luis López. The Iberian Peninsula Landscape of Tradition. In: VAN DOMMELEN, Peter; GÓMEZ BELLARD, Carlos (eds.), Rural Landscape of the Punic World. London-Oakville: Equinox, 2008, p. 76-100.

MARSTON, Elsa. The Phoenicians. New York: Benchmark Books/Marshall Cavendish, 2002. 
MAHJOUBI, Ammar. Punic Tunysia: $6^{\text {th }}$ century B.C to 146 B.C., Tunis: La Principale, 2002.

MARKOE, Glen. Peoples of the past, Phoenicians. Los Angeles: Berkeley, 2000.

MEZZOLANI, Antonella. Strutture abitative puniche in Norde Africa: note per un'analisi funzionale. In: AUBET, MarÍa Eugenia; BARTHÉLEMY, Manuela (orgs.), Actas del IV Congreso Internacional de Estudios Fenicios y Púnicos, vol. 3, Cádiz: Servicios de Publicaciones Universidad de Cádiz, 2000, p. 1223-1231.

MOSCATI, Sabatino. The Phoenicians. New York: Rizzoli, 1999.

PATETA, Luciano. Historía de la Arquitetura: Antologia Critica. Madrid: Celeste, 1984, p. 39-40.

PICARD, Gilbert Charles; PICARD, Colette Charles. La vie quotidienne à Carthage au temps d'Hannibal: IIIe siècle avant Jésus-Christ. Paris: Hachette, 1958.

RAMAZZINA, Adriana. Organização do Espaço e território na Fenícia na Idade do Ferro: Cidades e Necrópoles, Mare Nostrum, vol. 3, 2012, p. 157-174.

RIBICHINI, Sergio. Beliefs and Religious Life. In: MOSCATI, Sabatino (ed.), The Phoenicians. New York: Rizzoli, 1999, p. 120-152.

SÁEZ ROMERO, Antonio. Una parte más de Gadir: actividades económicas y culturales desarolladas por los fenicios en el actual territorio isleño. In: VIJANDE VILA, Eduardo; DIAZ RODRIGUEZ, Jose; SÁEZ ROMERO, Antonio (eds.), Historia y Arqueología en la primera década del siglo XXI en San Fernando. II Foro de Arqueología de San Fernando (Cádiz), 2011, p. 811.

SANTOS, Milton. Sociedade e Espaço: A Formação Social como Teoria e como Método. In: SANTOS, Milton. Da Totalidade do Lugar. São Paulo: Editora da Universidade de São Paulo, 2005, p. 21-41.

STANISLAV, Segert. Phoenician and the Eastern Canaanite Languages. In: HETZRON, Robert (ed.), The Semitic Languages. New York: Routledge, 1997a, p. 174-186.

STANISLAV, Segert. Phoenician and Punic Phonology. In: KAYE, Alan (ed.), Phonologies of Asia and Africa: Including Caucasus. Winona Lake: Eisenbrauns, vol. 1, 1997b, p. 55-64. 
TUSA, Vicenzo. Sicily. In: MOSCATI, Sabatino (ed.), The Phoenicians. New York: Rizzoli, 1999, p. 231-249.

TSIRKIN, Juli. El problema de la helenización de Cartago. In: AUBET, MarÍa Eugenia; BARTHÉLEMY, Manuela (orgs.), Actas del IV Congreso Internacional de Estudios Fenicios y Púnicos, vol. 3, Cádiz: Servicios de Publicaciones Universidad de Cádiz, 2000, p. 1233-1235.

VAN DOMMELEN, Peter. Colonial Interactions and Hybrid Practices. Phoenician and Carthaginian Settlement in the Ancient Mediterranean. In: STEIN, Gil (ed.), The Archaeology of Colonial Encounters. Comparative Perspectives. Santa Fe: School of American Research, 2005.

WHEELER, Mortimer. Archaeology from the Earth. Oxford: Clarendon Press, 1954.

ZAMORA LÓPEZ, José-Ángel; GENER BASALLOTE, José-María; NAVARRO GARCÍA, María-de-los-Ángeles; PAJUELO SÁEZ, JuanMiguel; TORRES ORTIZ, Mariano. Epígrafes fenicios arcaicos en la excavación del Teatro Cómico de Cádiz (2006-2010). In: MOSCATI, Sabatino (org.), Rivista di Studi Fenici, vol. 38, fasc. 2, 2010, p. 203-236.

\section{Internet}

LABECA - MAE/USP http:/ / labeca.mae.usp.br/ (Consultado em novembro de 2014) 